\title{
Letramento como prática social na formação de educadores e educadoras em um curso de licenciatura em Educação do Campo na UNEAL
}

\author{
Lettering as social practice in training educators in a licensing course in Countryside \\ Education at UNEAL
}

\author{
Sanadia Gama dos Santos \\ Doutora em Letras pela Universidade Estadual de Maringá, PR \\ Docente na Universidade Estadual de Alagoas, Brasil \\ sanadiasantos@yahoo.com.br
}

\begin{abstract}
Resumo
Este artigo tem como objetivo analisar o letramento como prática social e situada e como se constitui no processo de formação dos estudantes do curso de Letras no Programa de Licenciatura em Educação do Campo, da Universidade Estadual de Alagoas. Desse modo, a proposta apresentada demonstra algumas atividades ocorridas durante o desenvolvimento do percurso formativo e experiências propostas entre teoria e práxis situadas. Nesse caso, apresentamos as vivências durante a feira de Reforma Agrária, ocorrida concomitante às aulas de Literatura alagoana e Língua Portuguesa III. O recorte teórico está pautado nos novos Estudos do Letramento propostos por Street (2014), articulados na formação que envolve a proposta pedagógica dos princípios da Educação do Campo, Silva (2009). Os resultados apontam a importância dos letramentos na formação dos Educadores e Educadoras do campo, o que contribui para o fortalecimento do processo formativo nas escolas do campo.
\end{abstract}

Palavras-chave: Educação do Campo; Letramentos; Formação.

\begin{abstract}
This article aims to analyze literacy as a social and situated practice and how it is constituted in the process of training students of the Language course in the Degree Program in Rural Education from the State University of Alagoas. Thus, the proposal presented demonstrates some activities that occurred during the development of the formative path and experiences proposed between theory and situated praxis. In this case, we present the experiences during the Agrarian Reform fair, which occurred concurrently with classes in Alagoas Literature and Portuguese Language III. The theoretical framework is based on the New Literacy Studies developed by Street (2014), articulated in the training that involves the pedagogical proposal of the principles of Rural Education, Silva (2009). The results point to the importance of literacies in the education of rural educators, which contributes to the strengthening of the training process in rural schools.
\end{abstract}

Keywords: Field Education; Literacy; Formation.

\section{INTRODUÇÃO}

A criação de uma licenciatura em Educação do Campo (Procampo/UNEAL) surge não somente como uma necessidade estratégica educacional e econômica, mas também como um projeto que se opõe ao modelo de produção agrícola vigente, com base na monocultura da cana de açúcar, no latifúndio e na concentração de terra historicamente inseridos. 
Isso carece de formação específica para os agentes que estão atuando no campo e que, por sua vez, mantêm a invisibilidade de um modelo de formação de matrizes epistemológicas e de formação com o viés da Educação do Campo. Segundo Arroyo (2007, p. 2), "nosso sistema escolar é urbano, pensado sob o paradigma urbano", pois a cidade é pensada como espaço civilizatório por excelência. Isto é, a formação segue o modelo universalizante de educação, pensado na lógica do sistema dominante para satisfazer uma demanda de resultados numéricos, sem pensar nas especificidades dos sujeitos, tampouco na formulação de políticas públicas para as populações oriundas dessas regiões.

É nessa reflexão que a UNEAL, ciente da lacuna existente nessa área reflete e realiza a proposta de um programa de licenciatura para atender educadores e educadoras do campo, não somente àqueles que já atuam em espaços escolares, como também a educadores e educadoras oriundos de movimentos campesinos do estado de Alagoas.

Compreendermos que o conceito de Educação do Campo vai além do termo "educação" ou “escola", porque está relacionado com princípios e está alinhado a uma proposta político-filosófica de reivindicação de políticas públicas de reconhecimento e visibilidade para as experiências práticas vivenciadas pelos povos do campo.

Essa proposta surge das práticas cotidianas e experiências dos camponeses, bem como do meio dos movimentos campesinos enquanto forma de reivindicação e provocação para oficialização e reconhecimento da Educação do Campo como política pública relacionada à urgente necessidade de um modelo produtivo e sustentável a partir da implementação de um modelo de Reforma agrária no Brasil.

Em termos de proposta pedagógica, a formação docente compreendeu a alternância: tempo comunidade e tempo universidade. Nesse sentido, Silva (2009) embasou as matrizes metodológicas e epistemológicas da Educação do Campo a partir de três grandes pontos: identidade - diversos sujeitos que estão no campo; movimentos sociais - as práticas educativas a partir de cada experiência e organização; e Educação do campo como ato político e criativo.

$\mathrm{O}$ artigo está embasado na perspectiva dos Novos Estudos de Letramento que propõem compreender que as maneiras utilizadas pelas pessoas, ao interagirem por meio da leitura e escrita, têm relação com conhecimento, identidade e ser (STREET, 2003; 2014). Desse modo, letramento não é dado ou ensinado, mas traz efeitos sociais, é construído histórica, ideológica ou socialmente. Em termos de resultados, os dados deste trabalho mostram um modelo de letramento que possibilita a formação de educadores e educadoras em formato modular e dinâmico, o que teve implicações nas concepções de tempo e espaço propostos para as atividades e, consequentemente, no reconhecimento e legitimação de saberes e identidades locais. 


\section{EDUCAÇÃO DO CAMPO NO ESTADO DE ALAGOAS}

O estado de Alagoas possui extensão territorial de 27.767,661 km², com 102 municípios, e tem como capital a cidade de Maceió. O estado é oficialmente subdividido em três mesorregiões (Leste Alagoano, Agreste e Sertão Alagoano).

Segundo o documento normativo do Parecer de Educação do Campo do Estado de Alagoas (Parecer CEE/AL, 2014), nos últimos anos, tem ocorrido a falência de algumas usinas, maior fonte de renda do Estado, devido, em parte, à baixa produtividade da monocultura canavieira e a problemas climáticos de falta de chuva, mas, principalmente, à mundialização da economia, à transnacionalização do capital e à mecanização da agroindústria em outras regiões do país, que têm interferido na qualidade de vida dos povos do campo.

Por outro lado, a falta de pesquisa no campo, de implantação de outras fontes alternativas de geração de renda, de trabalho digno, de emprego de recursos tecnológicos, gerou a indigência social em todas as regiões geográficas do Estado e acelerou a expulsão do homem/mulher do campo para as grandes cidades.

Em todo o Estado de Alagoas, o latifúndio dificulta a manutenção da população no campo, tornando-o para o trabalhador rural que, por falta da posse da terra, trabalha "alugado", ou "de meia", ou como "arrendatário de uma safra", ou simplesmente diarista, o que não deixa de ser uma forma de subemprego e semiescravidão, quase sempre ganhando um salário precário e em precárias condições de sobrevivência.

Com essa realidade, não há uma seguridade no tocante aos direitos sociais de trabalho e, como consequência, os indicadores sociais no campo cada vez mais são os piores, pois acarretam alta de mortalidade infantil e baixos indicadores educacionais no tocante ao ingresso e oportunidade de escolarização, a exemplo do analfabetismo, evasão, repetência, distorção idade-série que nos têm acompanhado por todos esses anos.

Diante da pressão do latifúndio e da falta de recursos naturais que inviabilizam a sucessão rural e fortalecem o êxodo no campo, por falta de políticas públicas para os jovens rurais, o que acarreta o esvaziamento no campo e do trabalho na produção agrícola, observam-se também o descaso e a omissão dos governos municipais, estaduais.

Considerando esse cenário, há quatro décadas que os movimentos do campo se organizam para reivindicarem direitos para os povos do campo e, em Alagoas, são diversas as organizações que resistem e propõem projetos de assentamentos da reforma agrária, com o objetivo de proporcionar a produção de alimentos saudáveis, respeitando a cultura e buscando a garantia de direitos como educação, saúde, lazer, trabalho entre outros. 
Por isso, o Governo Federal investiu na expansão da rede escolar, induzindo um processo de repasse de responsabilidades aos municípios, ainda tendo a instância estadual como coordenadora do sistema. Nas décadas de 1980/90, o governo federal passou a lidar diretamente com os municípios, financiando principalmente a construção de prédios escolares através do FNDE - Fundo Nacional de Desenvolvimento do Ensino - que administra os recursos do Salário-Educação, quota federal.

Tal processo ocorreu sem nenhum planejamento de rede das organizações sociais, sem diálogo, numa prática de negociações políticas entre Prefeitos e MEC, mediada pelos parlamentares da bancada federal que ocuparam esse espaço através da atuação direta ou de escritórios especializados em projetos padronizados e "lobies".

Os movimentos sociais que atuam no estado são: o Movimento dos Trabalhadores Rurais Sem Terra (MST), Comissão Pastoral da Terra (CPT), Fundação dos Trabalhadores e Trabalhadoras na Agricultura do Estado de Alagoas (FETAG/AL), Movimento de Libertação dos Sem Terra (MLST). É por meio dessa luta que os movimentos empreendem conquistas no território, acesso a políticas públicas para a sustentabilidade e posse de terra na região, garantindo a sobrevivência e a permanência das famílias no campo, numa disputa contra a lógica hegemônica de esvaziamento e êxodo rural.

\section{ANÁLISE DOS DADOS}

Durante disciplinas integradas, um dos componentes modulares do curso, de modo a unir duas disciplinas da área de Letras - Metodologia do ensino da literatura e artes e Língua Portuguesa 3, volta-se à formação dos educadores de escolas rurais, de modo a integrar os saberes estudados, produzidos com suas vivências no sentido de refletir suas práticas no cotidiano da formação.

Nesse sentido, propusemos a realização das seguintes atividades:

- Na sexta-feira, foi exibido um vídeo sobre Paulo Freire e seu método baseado na ação-reflexão-ação e, a partir dos saberes construídos, das experiências e práxis locais que dão embasamento sobre os princípios do processo formativo, procurou-se ajudar os estudantes a refletirem sobre sua formação.

- No dia seguinte, os estudantes participaram da Feira da Reforma Agrária, organizada pelo Movimento dos Trabalhadores Sem-terra de Alagoas, organização esta que vem dialogando com o curso de licenciatura em Educação do campo, desde sua concepção até o processo formativo. Como atividade, solicitamos aos estudantes a confecção de um diário de bordo em 
que eles registrassem as experiências vivenciadas e reflexões obtidas no vídeo exibido no dia anterior.

A feira da reforma agrária é um espaço de divulgação das práticas realizadas pelo MST, como publicação de livros, produtos agrícolas produzidos pelos pequenos agricultores/as, poesia, música.

O objetivo da roda é socializar informações sobre os principais planos de luta e reivindicações do Movimento, resultantes do $2^{\circ}$ Encontro Nacional de Educadores da Reforma Agrária (ENERA).

$\mathrm{Na}$ roda de conversa, foram debatidas as resoluções e resultados do ENERA, tendo como tema central: "Um Brasil sem miséria, só uma política de Reforma agrária séria”!

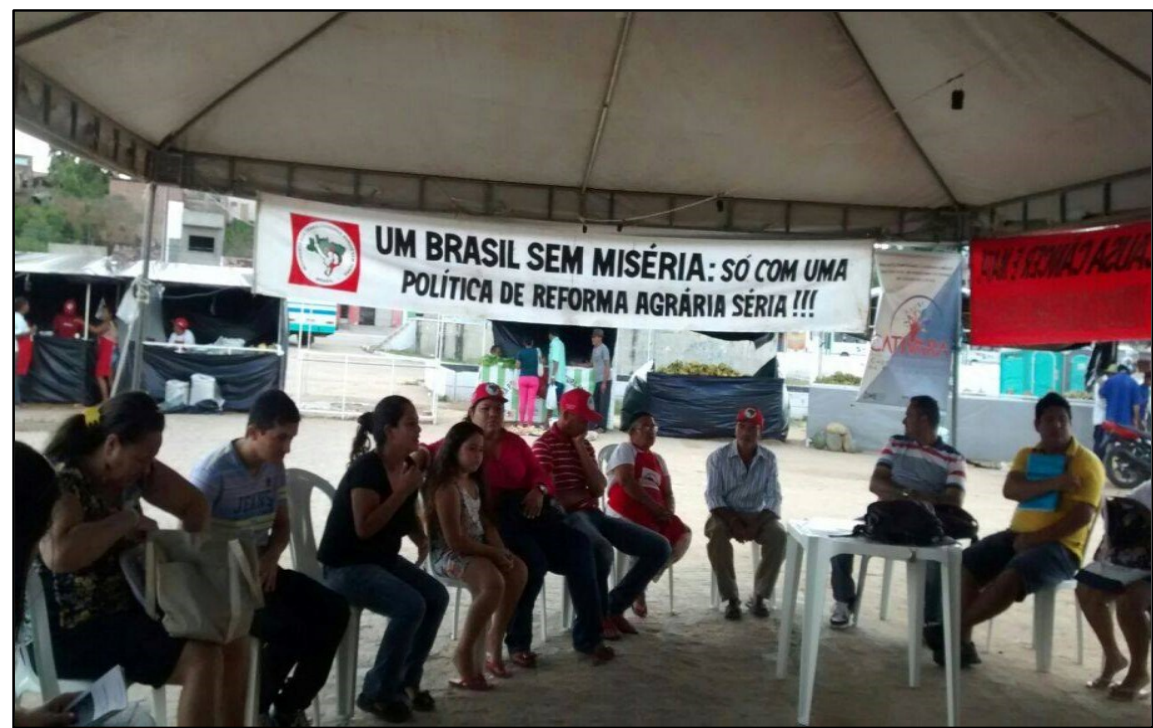

Figura 1 - Roda de conversa na Feira da Reforma Agrária de Arapiraca (11/2015). Fonte: Acervo da autora.

Durante o debate sobre o tema central, os estudantes interagiam, fazendo perguntas aos integrantes do movimento de modo a compreender esse universo de informações que reflete em sua formação.

Assim, temos:

\footnotetext{
"Para mim, esse debate é importante para aprendermos que não se ensina somente regras, mas também passamos a ter outros conhecimentos sobre educação do campo"- S1.
}

Nesse sentido, o conceito de práticas de letramento refere-se a concepções culturais mais amplas sobre a forma de pensar leitura e escrita em diferentes contextos. (STREET, 2003).

A leitura e a escrita estão de acordo com o que Freire (1989) afirma ser a leitura de mundo que precede a leitura da palavra, isso implica percepção crítica, interpretação e "reescrita" do lido. 
Assim, na sala de aula e na ida à feira como extensão da prática pedagógica realizada, é importante salientar que tanto os debates como também os textos escritos pelos estudantes a seguir trazidos, estão presentes no domínio da vida social e tudo isso se (inter)relaciona.

Com a linguagem, as pessoas podem esclarecer ou obscurecer, podem emancipar-se, tornarem-se autônomas nos seus saberes, nas suas decisões e atitudes, ou se iludirem e ficarem dependentes dos outros, sobretudo quando os outros utilizam mecanismos de poder diversos para evitar que a linguagem multiplique os significados e faça o pensamento fluir.

Então, pode-se dizer que as pessoas se entendem e se desentendem pela linguagem. Tanto podem dizer o que querem como podem ficar limitados a dizer o que os outros querem que digam.

Como produto da cultura e como prática cultural, as linguagens podem ser transformadas pela apropriação e pelo uso (prática) que as pessoas fazem quando as recebem, criando novos significados para os signos e novos signos para expressar pensamentos, sentimentos e acontecimentos.

Nos diários de bordo, atividade de escrita solicitada pelos professores, temos:

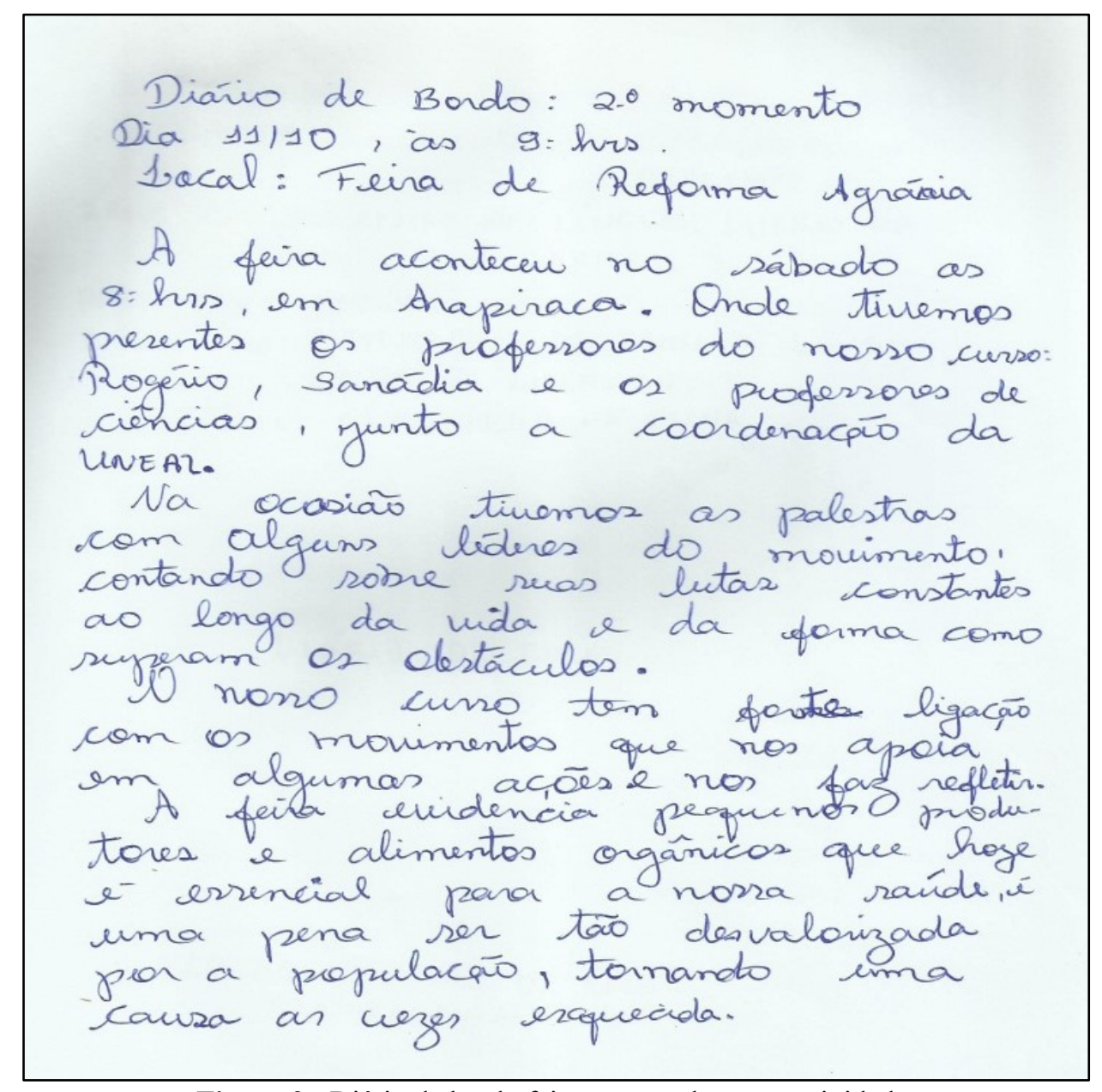

Figura 2 - Diário de bordo feito por estudante em atividade.

Fonte: Acerco da autora. 
no regundo dia estivemos no Parque eeci cunka, onde encontramos com aquipe da Reforma Agrarie, funtamentos com os proferrores do Procampo, pogério, Sanádia, Luana, gleica, Henrique, onde foi de batido cono funciono a Reforma Agrária, onde tivemos a Oportunedade de escutar os relatos de experiéncias de vida dar persou que forma sem terra, que l'um mo. vimento de pessoas que luta para ô desenvolvumento de vida de cada familia.

Ele lutam para contruir a Reforma Aqraria e un movimento pela Educacai do campo na conbruéa ta pedagogre socialiste para o confunto dos tralachadoos

Figura 3 - Diário de bordo feito por estudante.

Fonte: Acerco da autora.

Como vemos nas Figuras 2 e 3, os diários de bordo foram o registro das vivências e experiências realizadas pelos estudantes no dia da Feira da Agricultura familiar.

Na Figura 1, no primeiro parágrafo, a estudante faz a descrição temporal do ocorrido. No segundo, inter-relaciona a ida à feira com a ligação que os movimentos possuem com o curso, o que denota a construção coletiva da pauta de educação do campo construída com os movimentos campesinos.

A construção escrita das informações registradas evidencia os chamados eventos de letramento, a partir das ações vivenciadas na feira e na exibição do vídeo sobre o método Paulo Freire, ocorrido no dia anterior. Quanto aos eventos de letramento, Street (2000) defende que habilitam pesquisadores e praticantes a focarem uma situação particular, onde as coisas estão acontecendo e você pode vê-las acontecendo.

Assim, percebemos que as interações ocorridas nas atividades integradas até o registro escrito pelos estudantes estão atravessadas pelos elementos da vida social. As estratégias pedagógicas de aproximação entre teoria e prática trazida pelos professores conduzem e iluminam a criticidade - um dos objetivos da formação de professores do campo -, o que demonstra a forma que se dá entre a oralidade durante os debates e a sistematização das percepções e dos olhares dos estudantes. 


\section{LETRAMENTO NO CURSO DE LICENCIATURA EM EDUCAÇÃO DO CAMPO}

Tratamos do conceito de práticas de letramento emergido nas práticas sociais situadas, ou seja, as práticas sociais de leitura e de escrita estão presentes no cotidiano de toda sociedade e seus indivíduos. Assim, todas as práticas desenvolvidas como uso social corriqueiro são vistas como práticas de leitura e escrita daquilo que está em torno da cultura dos indivíduos e que é necessário para a vida humana.

Percebemos, portanto, que todas as atividades diárias constituem formas de utilização social da leitura e da escrita, constituídas, assim, como práticas de letramento. Nesse sentido, Street (2014) apresenta dois conceitos de letramento: o autônomo e o ideológico.

Essa visão ideológica de Street leva ao termo letramentos, no plural, como letramentos múltiplos, os usos sociais de leitura e escrita a que o sujeito fica exposto no seu contexto social.

Com relação ao modelo autônomo, refere-se, basicamente, às habilidades individuais do sujeito, e, no que diz respeito ao modelo ideológico, trata das práticas sociais que envolvem leitura e escrita em geral. No modelo autônomo, estão incluídas as atividades de processamento da leitura, tanto as que ocorrem de forma consciente quanto as inconscientes na construção de sentido do texto. Esse processo ideológico do letramento propõe uma prática social, pois os modos pelos quais as pessoas usam a leitura e a escrita estão vinculados às questões de conhecimento, identidade e modos de ser e estar no mundo, seja nas práticas sociais ou em contextos específicos.

Desse modo, os letramentos na formação dos educadores e educadoras do campo estarão dependentes desses contextos, onde as relações de poder desempenham um papel predominante.

$\mathrm{Na}$ proposta do curso, conforme descrevemos nos itens anteriores, identificamos que as relações de aprendizagens e interações estão intrínsecas entre realidade e conteúdo, por meio da Pedagogia da Alternância, intrínsecos ao processo formativo pedagógico que relaciona os assuntos teóricos da prática local onde cada estudante está inserido.

Nesse sentido, o letramento se constitui uma relação entre os sujeitos, sua prática pedagógica e os conteúdos orientados no curso. Assim, o modelo ideológico de letramento garante a constituição de saberes equitativos entre os estudantes, desmistificando um ensino de níveis constituído pelo pensamento hegemônico através da concepção de uma divisão do mundo dos "letrados" e "iletrados".

Tendo em vista essa maneira de pensar um novo modelo de letramento, cabem reflexões que nos levam a meditar sobre uma nova forma de ensino e sobre as diversas práticas de leitura e escrita que se inserem em condições específicas. 


\section{CONSIDERAÇÕES FINAIS}

O formato do curso de licenciatura em Educação do Campo da UNEAL volta-se para uma dimensão crítica, política e social, contudo a função da escrita transcende a lógica do modelo de letramento autônomo, compreendida como um produto em si mesmo.

No caso das atividades vivenciadas, percebe-se que a função do letramento abre espaço para a unidade da função da linguagem e sua representação no universo situacional das práticas vivenciadas pelos estudantes. Os registros são mediados pelo debate, pelo universo circundado na prática pedagógica dos professores, o que desencadeia um sentido de crítica e de relação da formação acadêmica com os princípios políticos da educação do campo trazidos pelos movimentos campesinos.

Os modos como os indivíduos abordam a escrita têm raízes em suas próprias concepções de aprendizagem, identidade e existência pessoal. Assim, letramento não é dado ou ensinado, mas traz efeitos sociais, é construído histórica, ideológica ou socialmente.

As concepções de linguagem situadas nas práticas sociais estão no eixo curricular do processo de formação dos estudantes/professores (as) do curso de licenciatura em Educação do Campo que se agregam às disciplinas das áreas de conhecimento.

Os dados do nosso trabalho mostram um letramento que possibilita a formação de educadores e educadoras do campo que compõem o formato modular e dinâmico do curso, o que teve implicações nas concepções de tempo e espaço propostas para as atividades e, consequentemente, no reconhecimento e legitimação de saberes e identidades locais.

\section{REFERÊNCIAS}

ARROYO, M. Indagações sobre currículo - educandos e educadores: seus direitos e o currículo. Brasília: Ministério da Educação, Secretaria de educação básica, 2007. 52p.

FREIRE, P. A importância do ato de ler em três artigos que se completam. 23. ed. São Paulo: Cortez, 1989. 49p.

Parecer no 113/2014 - CEE/AL. Maceió/Alagoas.

SILVA, M. S. As práticas pedagógicas das escolas do campo: A escola na vida e a vida como escola. 2009. 464 f. Tese (Doutorado em Educação) - Centro de Educação, Universidade Federal de Pernambuco, Recife, 2009.

STREET, B. Literacy events and literacy practices: theory and practice in the new literacy studies. 1. ed. Amsterdam: John Banjamins, 2000. 65p.

STREET, B. Abordagens alternativas ao letramento e desenvolvimento. Teleconferência Brasil sobre o letramento. Outubro de 2003. 
STREET, B. Letramentos sociais: abordagens críticas do letramento no desenvolvimento, na etnografia e na educação. Tradução Marcos Bagno. 1. ed. Parábola Editorial, 2014. 240p.

UNEAL. Projeto Político Pedagógico do Curso de Licenciatura em Educação do Campo. Arapiraca, 2009. 